Review article

\title{
The international prevalence of antidepressant use before, during, and after pregnancy: A systematic review and meta-analysis of timing, type of prescriptions and geographical variability
}

\author{
Nina M. Molenaar ${ }^{\mathrm{a}, \mathrm{b}, *}$, Babette Bais ${ }^{\mathrm{b}}$, Mijke P. Lambregtse-van den Berg ${ }^{\mathrm{b}, \mathrm{c}}$, Cornelis L. Mulder ${ }^{\mathrm{b}, \mathrm{d}}$, \\ Elizabeth A. Howell ${ }^{\mathrm{a}, \mathrm{e}, \mathrm{f}}$, Nathan S. Fox ${ }^{\mathrm{e}}$, Anna-Sophie Rommel ${ }^{\mathrm{a}}$, Veerle Bergink ${ }^{\mathrm{a}, \mathrm{b}, \mathrm{e}, \mathrm{f}}$, \\ Astrid M. Kamperman ${ }^{\mathrm{b}, \mathrm{d}}$ \\ ${ }^{a}$ Department of Psychiatry, Icahn School of Medicine at Mount Sinai, New York, United States \\ ${ }^{\mathrm{b}}$ Department of Psychiatry, Erasmus Medical Center, Rotterdam, the Netherlands \\ ${ }^{\mathrm{c}}$ Department of Child and Adolescent Psychiatry/Psychology, Erasmus Medical Center, Sophia's Children Hospital, Rotterdam, the Netherlands \\ ${ }^{\mathrm{d}}$ Epidemiological and Social Psychiatric Research Institute, Erasmus Medical Center, Rotterdam, the Netherlands \\ e Department of Obstetrics, Gynecology and Reproductive Science, Icahn School of Medicine at Mount Sinai, New York, United States \\ ${ }^{\mathrm{f}}$ Blavatnik Family Women's Health Research Institute, Icahn School of Medicine at Mount Sinai, New York, United States
}

\section{A R T I C L E I N F O}

\section{Keywords:}

Antidepressants

Pregnancy

Prevalence

Epidemiology

Systematic review

Meta-analysis

\begin{abstract}
A B S T R A C T
Background: Antidepressant use during pregnancy has increased over the last decades, while safety has been under debate. Our aim was to measure the international prevalence of antidepressant use before, during, and after pregnancy and examine timing, type of prescriptions and geographic variability.

Methods: We searched Embase, Medline Ovid, Web of Science, Cochrane Central and Google Scholar from their inception until February 19, 2019. We determined pooled prevalence estimates of antidepressants before, during, and after pregnancy, as well as stratified according to substantive variables.

Results: We identified 40 cohorts from 15 countries, together reporting on 14,072,251 pregnancies. Included studies had a low risk of bias, often reporting on large representative cohorts. Selective serotonin reuptake inhibitors (SSRIs) were the most commonly used antidepressants during pregnancy, with an international prevalence estimate of $3.0 \%$ (95\%CI 2.3;3.7). While Europe and Australasia had pooled prevalence estimates of $1.6 \%$ and $1.3 \%$ respectively, Northern America had a prevalence estimate of $5.5 \%(Q$-value $=126.19 ; \mathrm{df}=2 ; p$ value $<0.01)$. Highest SSRI prevalence rates were found for sertraline $(1.10 \%)$, followed by citalopram and fluoxetine $(0.77 \%$ and $0.76 \%$ respectively) ( $Q$-value $=121.25 ; \mathrm{df}=5 ; p$-value $<0.01)$. Qualitative analysis indicated an increase in antidepressant use over subsequent calendar years.

Limitations: Substantial heterogeneity remained unaccounted for throughout the analyses, even after accounting for hypothetical contributors.

Conclusions: This meta-analysis revealed substantial regional differences in antidepressant use around pregnancy, which could be due to variability in prescription behavior, healthcare seeking behavior and organization of healthcare. There is an urgent need for evidence on effectiveness, benefit, and harm of antidepressants during pregnancy to guide clinical practice.
\end{abstract}

\section{Introduction}

Prescribed medication use during pregnancy is common, with overall estimates in developed countries ranging from $27 \%$ to $93 \%$, excluding vitamins and minerals (Daw et al., 2011). Over the last decades, this use of prescription medication during pregnancy has increased by more than $60 \%$ (Mitchell et al., 2011), and antidepressants greatly contribute to this increase (Andrade et al., 2016; Charlton et al., 2015; Cooper et al., 2007). In the general population, antidepressants are now among the top three most commonly prescribed therapeutic drug classes in the United States (Pratt et al., 2017). Antidepressants showed the largest increase in prescriptions during pregnancy over time, compared to other drugs associated with potential harmful neonatal effects (van Gelder et al., 2014).

\footnotetext{
* Corresponding author at: Department of Psychiatry, Icahn School of Medicine at Mount Sinai, 1425 Madison Avenue, 10029 New York, NY, USA.

E-mail address: nina.molenaar@mssm.edu (N.M. Molenaar).
} 
The use of antidepressants during pregnancy has been under debate, because evidence on adverse fetal and child outcomes is inconclusive (Simoncelli et al., 2010). Studies have found associations of maternal antidepressant use with increased risks for cardiovascular malformations (Grigoriadis et al., 2013b), persistent pulmonary hypertension of the neonate (Kieler et al., 2012), poor neonatal adaptation (Grigoriadis et al., 2013a), preterm delivery and lower birth weight (Ross et al., 2013), altered fetal brain development (LugoCandelas et al., 2018), and psychiatric disorders in the offspring such as mood disorders, autism spectrum disorders and behavioral disorders including ADHD (Liu et al., 2017). Other studies failed to find these increased risks or observed only modest effects (Furu et al., 2015; Huybrechts et al., 2015; Hviid et al., 2013). Since studies on antidepressants in pregnancy are not typically randomized, it is often difficult to determine if reported adverse outcomes associated with antidepressants are related to the medication itself, the underlying maternal mental illness, genetic risk differences between women with and without mental illness, other confounding exposures such as alcohol, smoking, substance abuse, nutrition, and other medications, or socioeconomic differences between cohorts. As a result, the risk of these medications is not definitively established. Coupled with the lack of robust data on alternative therapies while discontinuing antidepressants in pregnancy, both women and clinicians lack clear guidance whether they should continue antidepressants during pregnancy or not. Consequently, $50 \%$ of women decide to discontinue their antidepressants, either before or during pregnancy (Charlton et al., 2015; Hanley and Mintzes, 2014; Molenaar et al., 2019).

Limited data suggest that prescription rates and antidepressants use vary by country and study setting (Charlton et al., 2015). We performed a systematic review and meta-analysis to examine international prevalence rates and patterns of antidepressant use before, during, and after pregnancy. We explored use in the different trimesters, examined geographical differences in prescription patterns and examined prevalence trends over time.

\section{Methods}

\subsection{Literature search}

This systematic review and meta-analysis was conducted and reported in line with the PRISMA guidelines (Liberati et al., 2009). The protocol was registered in PROSPERO (CRD42018116978). All large databases, including embase.com, Medline Ovid, Web of Science, Cochrane Central and Google Scholar were searched by a medical information specialist from inception to February 19, 2019, using search terms describing types of antidepressants, the target population and type of study (full search strategy available in the Online Resource).

\subsection{Eligibility criteria}

Studies were eligible if they were peer-reviewed, written in English, and if they described a population of women using antidepressants either the year before pregnancy, during pregnancy, or the first postpartum year. The following groups of antidepressants were included: selective serotonin reuptake inhibitors (SSRIs), serotonin and norepinephrine reuptake inhibitors (SNRIs), tricyclic antidepressants (TCAs), monoamine oxidase inhibitors (MAOIs), and other antidepressants (e.g. tetracyclics). To avoid unreliable comparisons, studies that did not specify on which groups of antidepressants they reported were excluded, as underreporting could not be ruled out (e.g. a study reporting on 'antidepressants' could be a study only including TCAs, thereby leading to a gross underreporting of the prevalence of antidepressants in the perinatal period). All observational studies reporting the antidepressant prevalence in a certain time period with a known cohort size or reporting a numerator and denominator were included. We excluded case-control studies, case reports, case series, reviews, conference abstracts, and studies reporting on antidepressant use without specifying the country or perinatal phase. We also excluded studies focused on specific subpopulations (population not suitable) instead of general prevalence of antidepressant use (e.g. antidepressant use in pregnant women suffering from a major depressive disorder, or antidepressant use in a population of women with birth defects in the offspring), as we were interested in the population-based prevalence rates.

\subsection{Study selection and data extraction}

Duplicates were screened and removed with the citation manager EndNote. Two reviewers (NMM, BB) independently screened the titles and abstracts and assessed the full text of potential eligible studies. When multiple papers reported on the same cohort, the paper with highest level of detail was included (e.g. a paper reporting on multiple antidepressant subgroups). Two reviewers (NMM, BB) independently extracted data using a standardized data extraction form. We extracted the number of pregnancies aided by antidepressant use specified to type of antidepressant and perinatal phase (numerator) and the total number of pregnancies in the corresponding perinatal phase (denominator) for the entire cohort and, when available, per subsequent calendar years for time trend analysis. We report whether the outcome describes all pregnancies or life births only and whether multiple pregnancies and consecutive pregnancies were included. Additionally, data was extracted regarding the study period, geographic location, type of study (prospective, retrospective), in- and exclusion criteria, and definition of antidepressant use (dispensing, prescription, self-report). Disagreements between reviewers were reconciled among NMM, BB and AMK.

\subsection{Quality assessment}

The quality of the studies related to antidepressant prevalence was assessed informed by the Joanna Briggs Institute's critical appraisal checklist for studies reporting prevalence data (Munn et al., 2015, 2014). Potential bias with regard to the following quality criteria was assessed: 1) was the sample frame appropriate to address the target population, 2) were study participants sampled in an appropriate way, 3) was the sample size adequate, 4) were study subjects and setting described in detail, and 5) was the response rate adequate. The sample frame was deemed appropriate when the sample was a valid representation of the general population of the country where the study was performed (e.g. birth registers covering the entire country are appropriate, while a cohort from a single general hospital is not). There was an appropriate sampling method when in- and exclusion criteria were not restrictive. Sample size was considered adequate when larger than 2000 participants (Naing et al., 2006).

\subsection{Procedure for meta-analyses}

Data analysis was carried out in STATA (version 15, STATA Corporation, College Station, TX, USA) using metaprop procedures (Nyaga et al., 2014). Overall pooled estimates were calculated with inverse-variance weights obtained from the random-effects model using the method of DerSimonian and Laird. Confidence intervals of the unique studies were computed with the exact method. We calculated an overall prevalence and $95 \%$ Confidence Interval (CI) per antidepressant, per perinatal phase (before, during, after), and per geographic region. Subgroup differences were tested using the randomeffects model. Random-effects was chosen over fixed-effects analysis as substantial heterogeneity was expected (Munn et al., 2015). We reported Cochran's Q-, $I^{2}$-statistics and significance levels. We also decided to calculate $95 \%$ prediction intervals using the method suggested by Higgins et al. given the substantial heterogeneity found (Higgins et al., 2009). We qualitatively reviewed the impact of time on 
prevalence rates due to limited reported prevalence rates per calendar year. Additional time trend analysis using random-effects meta-regression analysis can be found in the Online Resource.

Sensitivity analysis were used to assess the robustness of our findings and to explore potential sources of heterogeneity. Per type of antidepressant we estimated the overall prevalence using both randomand fixed-effect calculation to evaluate the impact of the estimation method. We then examined prevalence rates of SSRIs during pregnancy in more detail, as that was the most frequently studied and most commonly used type of antidepressant. We estimated the impact of methodological factors, study quality and bias on the prevalence of SSRI use during pregnancy. We reported Cochran's $Q$ and significance levels.

We used funnel plots to visually assess the presence of small-study effects per pregnancy phase among studies reporting on SSRI use, and Egger's regression-based test for formal assessment (results in Online Resource).

\section{Results}

\subsection{Selection of studies}

The literature search produced a set of 6618 articles after de-duplication, which were then reviewed based on titles and abstracts by two independent reviewers, resulting in an initial selection of 354 articles. After full-text assessment of the 354 articles, 39 articles, reporting on 40 cohorts (Charlton et al. reports on two separate Italian cohorts) (Charlton et al., 2015), were included (Fig. 1). Interrater reliability with respect to selected articles was considered good (interrater agreement: 96\%, kappa: 0.66 (95\%CI: 0.62-0.70).

\subsection{Study characteristics}

Prevalence data for antidepressant use in the perinatal period was provided for a total sample of 14,072,251 pregnancies from 15 highincome countries. Sample size per cohort ranged between 436 and $1,895,519$ pregnancies. Thirty-five cohorts $(87.5 \%)$ were retrospective in nature. Fifteen cohorts included data on the year before conception, all 40 cohorts focused on the pregnancy period itself (either on the complete pregnancy or on one or more trimesters) and eight cohorts included data from the first postpartum year. Most cohorts included information on SSRIs $(k=39)$, while some also focused on SRNIs $(k=12)$, TCAs $(k=15)$, MAOi $(k=4)$ or other forms of antidepressants $(k=12)$. Prevalence rates were reported across a 26-year period (from 1989 to 2015). Detailed characteristics of all cohorts are provided in Supplementary Table 1 and 2 in the Online Resource.

\subsection{Prevalence estimates per perinatal phase for all major antidepressant groups}

Fig. 2 presents the international random-effects prevalence estimates for all major antidepressant groups before, during, and after pregnancy. SSRIs were most often prescribed and examined (prevalence ranging from $3.01 \%$ to $4.66 \%$ ), followed by SNRIs (prevalence ranging from $0.55 \%$ to $0.73 \%$ ) and TCAs (prevalence ranging from $0.38 \%$ to $0.62 \%)$. Only two cohorts reported on MAOIs. SSRIs showed a small decrease in prevalence from preconception to pregnancy (from $3.50 \%$ to $3.01 \%$ ) with a subsequent increase from pregnancy to the postpartum period $(3.01 \%-4.66 \%)$. These fluctuations did not reach statistical significance $(Q$-value $=4.60 ; \mathrm{df}=2 ; p$-value $=0.10)$. Forest plots of SSRI prevalence per perinatal phase can be found in the Online Resource (Supplementary Figs. 1-3). Prediction intervals were wide due to substantial heterogeneity.

\subsection{Prevalence estimates of SSRIs during pregnancy}

Fig. 3 presents the international random-effects prevalence estimates of SSRIs during pregnancy stratified by substantive variables. Out of the 40 cohorts, 22 cohorts reported on the prevalence of SSRI use for a specific trimester. Prevalence rates slightly decreased, albeit nonsignificantly so, from $2.46 \%$ in the first trimester to $1.59 \%$ in the second trimester, increasing to $1.84 \%$ in the third trimester $(Q$-value $=4.34$; $\mathrm{df}=2 ; p$-value $=0.11$ ). The observed prevalence estimates per trimester tend to be lower than the overall prevalence estimate during complete pregnancy (3.01\%). Women may discontinue or initiate SSRIs during any given trimester and are therefore not always represented in each separate trimester. Ten cohorts reported on prevalence rates per specific SSRI. Highest SSRI prevalence rates were found for sertraline (1.10\%), followed by citalopram and fluoxetine $(0.77 \%$ and $0.76 \%$ respectively; $Q$-value $=121.25 ; \mathrm{df}=5 ; p$-value $<0.01$ ).

\subsection{Variation in prevalence estimates per geographical region}

Fig. 4 represents the random-effects prevalence estimates of SSRIs during pregnancy per geographical region. Prevalence rates were lowest in Australasia, with an overall estimate of $1.35 \%(95 \% \mathrm{CI}$ $0.20 ; 2.50$, prevalence interval $0.00 ; 6.98$ ). Three out of four Australasian cohorts reported a rate equal to or lower than $0.65 \%$. In Europe, the overall estimate was slightly higher with $1.64 \%(95 \% \mathrm{CI}$ $1.42 ; 1.85$, prevalence interval $0.79 ; 2.48$ ). Nine cohorts reported on prevalence rates in Northern America, coming to an overall estimate of $5.46 \%$ (95\%CI 4.83;6.10, prevalence interval 3.05;7.87). The study by Cooper et al. (2007), reporting the prevalence in a cohort from 1999 to 2003, had the largest prevalence with $10.20 \%$. The study by Figueroa (2010), reporting on a cohort from 1997 to 2002, had the lowest prevalence with $2.41 \%$. Both of these studies had a high risk of bias regarding their sample frame (Supplementary Fig. 4 in the Online Resource). Differences between geographical regions were statistically significant $(Q$-value $=126.19 ; \mathrm{df}=2 ; p$-value $<0.01)$.

\subsection{Prevalence rates over time}

Of all 40 cohorts, only two reported prevalence rates (including numerator and denominator) over a series of subsequent calendar years ( Huybrechts et al., 2015; Molenaar et al., 2019). Twelve cohorts from six countries mentioned prevalence rates in the first and last year of their cohort (in percentages, without numerator and denominator, therefore unsuitable for meta-regression). These prevalence rates are presented in Table 1 . The majority of cohorts (90\%) with a start date from 1992 to 2001 showed an increase in antidepressant use during pregnancy over time. Andrade et al. (Andrade et al., 2016), studying a cohort of 1,895,519 deliveries between 2001 and 2013, observed the largest increase over time. In this cohort, the SSRI prevalence during pregnancy increased from $1.7 \%$ in 2001 to $14.9 \%$ in 2010 . In contrast, cohorts with a start date from 2004 to 2010 either showed stabilization or a slight decrease in antidepressant use during pregnancy over time. Quantitative analysis using meta-regression can be found in the Online Resource.

\subsection{Risk of bias of the studies}

Overall, included studies had a low risk of bias, often reporting on large representative cohorts. The sample frame was considered inappropriate in $51.3 \%$ of the included studies. For example, Boukhris et al. (2016) and Brown et al. (2017) predominantly included women of lower socio-economic status, while Wichman et al. (2009) only included women from a single hospital in one state. Sampling method was a potential risk in $33.3 \%$ of the studies. For example, Figueroa (2010) only included women with a hospitalized delivery. The gross majority of the studies were considered low risk of bias with 

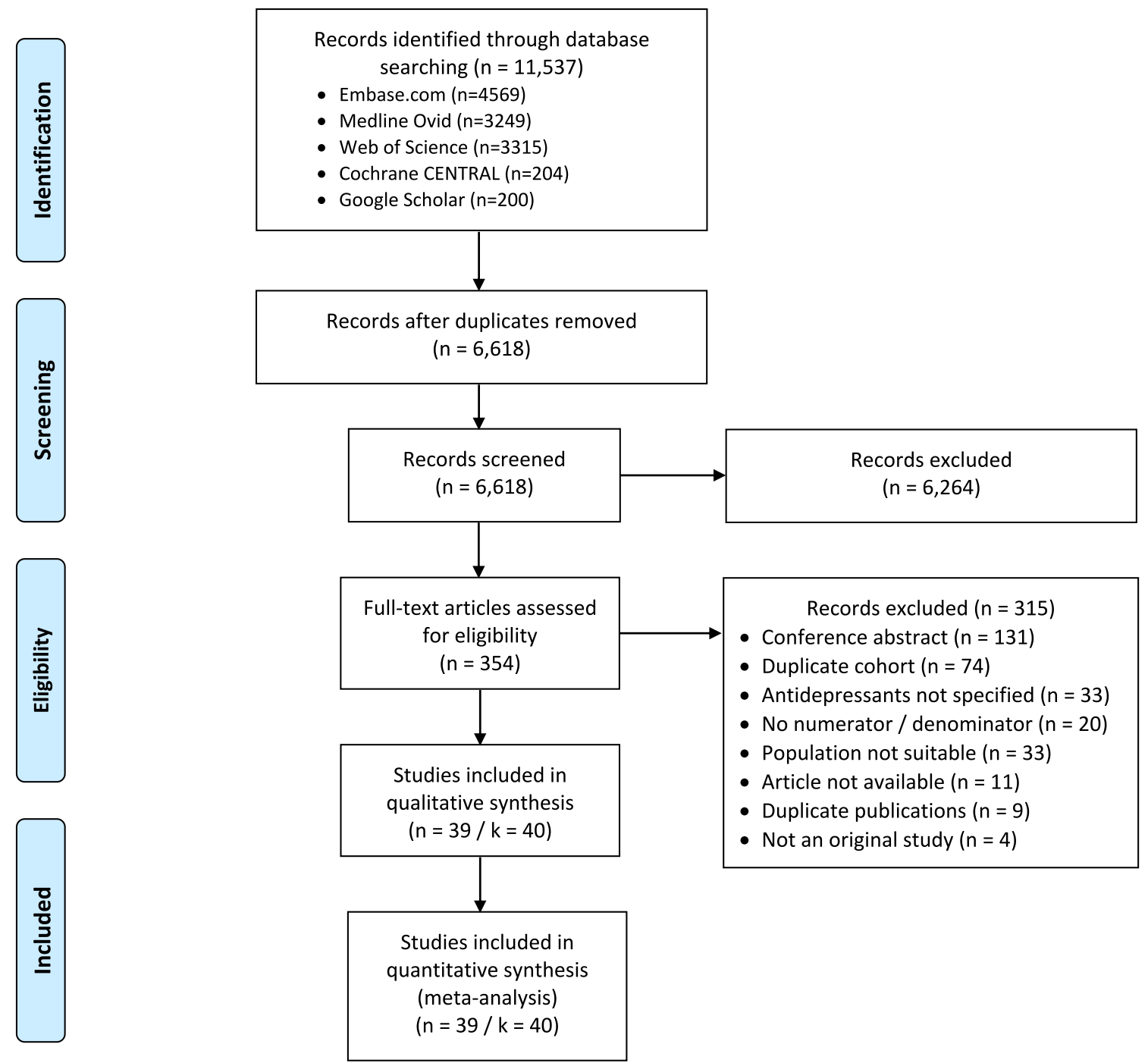

Fig. 1. PRISMA flow diagram of study inclusion

\begin{tabular}{|c|c|c|c|c|c|c|c|c|c|}
\hline & \multicolumn{9}{|c|}{ Prevalence of antidepressants in the perinatal period } \\
\hline & $\begin{array}{l}\text { No. of } \\
\text { cohorts }\end{array}$ & $\begin{array}{l}\text { Pooled } \\
\text { sample size }\end{array}$ & $\begin{array}{l}\text { No. of } \\
\text { countries }\end{array}$ & $\begin{array}{l}\text { Pooled } \\
\text { prevalence } \\
\%\end{array}$ & $\begin{array}{l}\text { Forest plot } \\
\text { of pooled } \\
\text { random } \\
\text { effect } \\
\text { prevalence }\end{array}$ & $95 \% \mathrm{CI}$ & $\begin{array}{l}\text { Prediction } \\
\text { interval }\end{array}$ & $\mathrm{I}_{2}$ statistic $(\%)$ & $\begin{array}{l}\mathrm{Q} \text { statistic (df; } \\
p \text {-value) }\end{array}$ \\
\hline \multicolumn{10}{|l|}{ SSRIs } \\
\hline Year before pregnancy & 14 & $4,783,284$ & 7 & $3 \cdot 50$ & $\rightarrow$ & $(2 \cdot 40 ; 4 \cdot 60)$ & $(0 \cdot 00 ; 8 \cdot 23)$ & $99 \cdot 97$ & \\
\hline During pregnancy & 24 & $8,135,384$ & 13 & $3 \cdot 01$ & $\rightarrow$ & $(2 \cdot 29 ; 3 \cdot 74)$ & $(0 \cdot 00 ; 6 \cdot 84)$ & $99 \cdot 98$ & \\
\hline Year after pregnancy & 7 & $1,394,101$ & 4 & $4 \cdot 66$ & $\longrightarrow$ & $(3 \cdot 34 ; 5 \cdot 98)$ & $(0 \cdot 00 ; 9 \cdot 54)$ & $99 \cdot 93$ & $4 \cdot 60(2 ; 0 \cdot 10)$ \\
\hline \multicolumn{10}{|l|}{ SNRIs } \\
\hline Year before pregnancy & 3 & 921,356 & 2 & 0.68 & $\mathbf{v}$ & $(0 \cdot 43 ; 0 \cdot 94)$ & $N A \mathrm{~b}$ & $99 \cdot 49$ & \\
\hline During pregnancy & 8 & $2,597,070$ & 5 & $0 \cdot 73$ & $\downarrow$ & $(0 \cdot 54 ; 0 \cdot 92)$ & $(0 \cdot 02 ; 1 \cdot 44)$ & $99 \cdot 83$ & \\
\hline Year after pregnancy & 1 & 488,887 & 1 & $0 \cdot 55$ & $\checkmark$ & $(0 \cdot 53 ; 0 \cdot 57)$ & $N A$ & $N A$ & $0.09(1 ; 0.77)$ \\
\hline \multicolumn{10}{|l|}{ TCAs } \\
\hline Year before pregnancy & 5 & $1,321,633$ & 3 & 0.52 & $\checkmark$ & $(0 \cdot 26 ; 0 \cdot 79)$ & $(0 \cdot 00 ; 1 \cdot 55)$ & $99 \cdot 81$ & \\
\hline During pregnancy & 9 & $2,892,610$ & 5 & $0 \cdot 38$ & 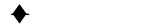 & $(0 \cdot 29 ; 0 \cdot 46)$ & $(0 \cdot 06 ; 0 \cdot 69)$ & $99 \cdot 61$ & \\
\hline Year after pregnancy & 3 & 914,939 & 2 & 0.62 & 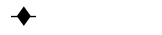 & $(0 \cdot 01 ; 1 \cdot 22)$ & $N A$ & $99 \cdot 91$ & $1.63(2 ; 0.44)$ \\
\hline \multicolumn{10}{|l|}{ MAOi } \\
\hline Year before pregnancy & $N A$ & $N A$ & $N A$ & $N A$ & & NA & NA & $N A$ & \\
\hline During pregnancy & 2 & 233,934 & 2 & 0.00 & $\bullet$ & $(0 \cdot 00 ; 0 \cdot 00)$ & $N A$ & $N A$ & \\
\hline \multirow[t]{2}{*}{ Year after pregnancy } & $N A$ & $N A$ & $N A$ & $N A$ & & $N A$ & $N A$ & $N A$ & $N A$ \\
\hline & & & & & $3 \%$ & & & & \\
\hline
\end{tabular}

Fig. 2. Global prevalence estimates per perinatal phase ${ }^{\mathrm{a}}$.

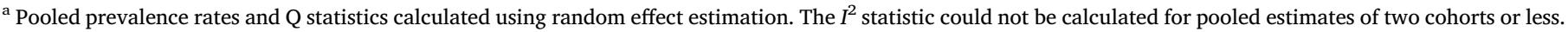
The $Q$ statistic only reflects tested differences between categories with $n>1 .{ }^{\mathrm{b}} N A=$ Not Applicable 


\begin{tabular}{|c|c|c|c|c|c|c|c|c|c|}
\hline & \multicolumn{9}{|c|}{ Prevalence of selective serotonin reuptake inhibitors during pregnancy } \\
\hline & $\begin{array}{l}\text { No. of } \\
\text { cohorts }\end{array}$ & $\begin{array}{l}\text { Pooled } \\
\text { sample size }\end{array}$ & $\begin{array}{l}\text { No. of } \\
\text { countries }\end{array}$ & $\begin{array}{l}\text { Pooled } \\
\text { prevalence } \\
\%\end{array}$ & $\begin{array}{l}\text { Forest plot of } \\
\text { pooled random } \\
\text { effect } \\
\text { prevalence }\end{array}$ & $95 \% \mathrm{CI}$ & $\begin{array}{l}\text { Prediction } \\
\text { interval }\end{array}$ & $\begin{array}{l}\text { I2 statistic } \\
(\%)\end{array}$ & $\begin{array}{l}\text { Q statistic (df; } p \text { - } \\
\text { value) }\end{array}$ \\
\hline Overall pooled prevalence & 24 & $8,135,384$ & 13 & $3 \cdot 01$ & & $(2 \cdot 29 ; 3 \cdot 74)$ & $(0 \cdot 00 ; 6 \cdot 84)$ & $99 \cdot 98$ & \\
\hline \multicolumn{10}{|l|}{ Prevalence by trimester } \\
\hline First trimester & 22 & $7,566,490$ & 11 & $2 \cdot 46$ & $\rightarrow$ & $(1 \cdot 82 ; 3 \cdot 10)$ & $(0 \cdot 00 ; 5 \cdot 73)$ & $99 \cdot 98$ & \\
\hline Second trimester & 18 & $6,625,968$ & 9 & $1 \cdot 59$ & $\rightarrow$ & $(1 \cdot 07 ; 2 \cdot 11)$ & $(0 \cdot 00 ; 4 \cdot 04)$ & $99 \cdot 97$ & \\
\hline Third trimester & 20 & $11,272,913$ & 10 & $1 \cdot 84$ & $\vdash$ & $(1 \cdot 32 ; 2 \cdot 36)$ & $(0 \cdot 00 ; 4 \cdot 39)$ & $99 \cdot 98$ & $4 \cdot 34(2 ; 0 \cdot 11)$ \\
\hline \multicolumn{10}{|l|}{ Prevalence by individual SSRI } \\
\hline Citalopram & 11 & $4,009,196$ & 5 & $0 \cdot 77$ & 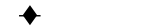 & $(0 \cdot 45 ; 1 \cdot 08)$ & $(0 \cdot 00 ; 2 \cdot 04)$ & $99 \cdot 94$ & \\
\hline Escitalopram & 9 & $3,876,322$ & 4 & $0 \cdot 47$ & & $(0 \cdot 18 ; 0 \cdot 77)$ & $(0 \cdot 00 ; 1 \cdot 59)$ & $99 \cdot 96$ & \\
\hline Fluoxetine & 12 & $4,072,591$ & 7 & $0 \cdot 76$ & 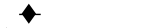 & $(0 \cdot 44 ; 1 \cdot 08)$ & $(0 \cdot 00 ; 2 \cdot 07)$ & $99 \cdot 94$ & \\
\hline Fluvoxamine & 6 & $2,315,809$ & 5 & $0 \cdot 01$ & $\diamond$ & $(0.00 ; 0.02)$ & $(0 \cdot 00 ; 0 \cdot 04)$ & $96 \cdot 07$ & \\
\hline Paroxetine & 11 & $3,729,292$ & 6 & $0 \cdot 56$ & $\downarrow$ & $(0 \cdot 41 ; 0 \cdot 71)$ & $(0 \cdot 00 ; 1 \cdot 15)$ & $99 \cdot 79$ & \\
\hline \multirow[t]{2}{*}{ Sertraline } & 12 & $4,072,591$ & 6 & $1 \cdot 10$ & $\vdash$ & $(0 \cdot 60 ; 1 \cdot 60)$ & $0 \cdot 00 ; 3 \cdot 14)$ & $99 \cdot 97$ & $121 \cdot 25(5 ;<0 \cdot 01)$ \\
\hline & & & & & $3 \%$ & $\%$ & & & \\
\hline
\end{tabular}

Fig. 3. Global random effects prevalence estimates of SSRIs during pregnancy stratified by substantive variables ${ }^{\mathrm{a}}$.

${ }^{a}$ Pooled prevalence rates and Q statistics calculated using random effect estimation.

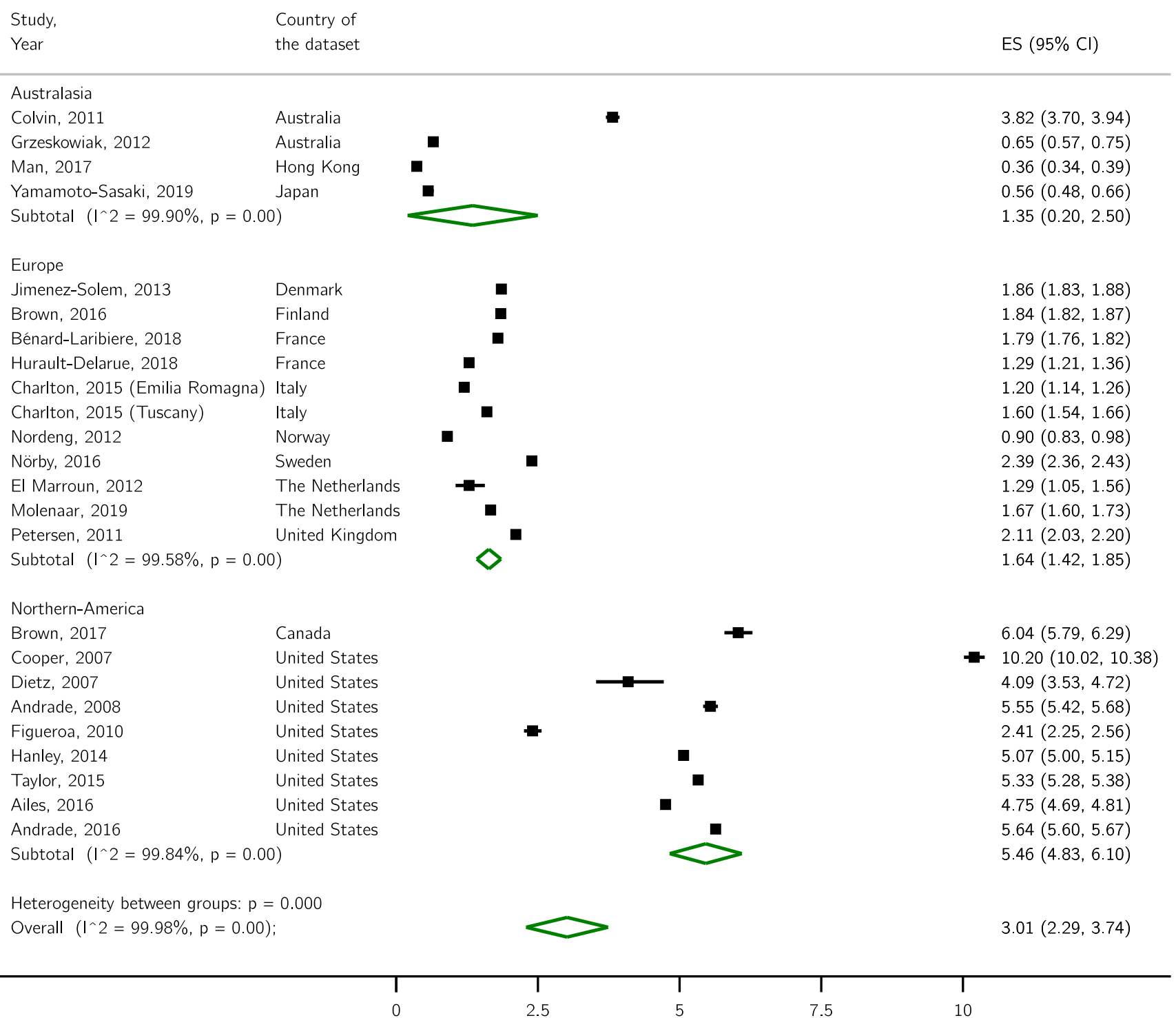

Fig. 4. Prevalence estimates of SSRIs during pregnancy stratified by region.

regards to sample size, description of subjects and setting, and response rate (Supplementary Figs. 4 and 5 in the Online Resource).

\subsection{Sensitivity analysis}

The overall prevalence estimates per type of antidepressant differed substantially between random- and fixed-effect calculations. The prevalence estimate for SSRIs during pregnancy was $2.33 \%(95 \% \mathrm{CI}$ 
Table 1

Studies reporting prevalence rates of antidepressants during pregnancy over time.

\begin{tabular}{|c|c|c|c|c|c|c|c|}
\hline Study & Start & $\%$ & End & $\%$ & & Country & AD type \\
\hline Petersen (2011) & 1992 & 0.8 & 2006 & 3.3 & 수 & $\begin{array}{l}\text { United } \\
\text { Kingdom }\end{array}$ & Overall \\
\hline \multirow[t]{2}{*}{ Andrade (2008) } & 1996 & 2.0 & 2005 & 7.6 & 1 & USA & Overall \\
\hline & 1996 & 1.5 & 2005 & 6.2 & 1 & & SSRIs \\
\hline Jimenez-Solem (2013) & 1997 & 0.2 & 2009 & 3.2 & 1 & Denmark & Overall \\
\hline \multirow[t]{2}{*}{ Cooper (2007) } & 1999 & 5.7 & 2003 & 13.4 & 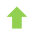 & USA & Overall \\
\hline & 1999 & 2.9 & 2003 & 10.2 & 1 & & SSRIs \\
\hline Molenaar (2019) & 1999 & 0.8 & 2014 & 2.1 & 个 & $\begin{array}{l}\text { The } \\
\text { Netherlands }\end{array}$ & SSRIs \\
\hline Huybrechts (2015) & 2000 & 2.3 & 2010 & 2.6 & $\Rightarrow$ & USA & SSRIs \\
\hline Andrade (2016) & 2001 & 1.7 & 2010 & 14.9 & 1 & USA & SSRIs \\
\hline Charlton (2015) & 2004 & 1.4 & 2009 & 1.8 & $\Rightarrow$ & $\begin{array}{l}\text { Italy } \\
\text { (Tuscany) }\end{array}$ & SSRIs \\
\hline Charlton (2015) & 2004 & 1.4 & 2009 & 1.3 & $\Rightarrow$ & $\begin{array}{l}\text { Italy (Emilia } \\
\text { Romagna) }\end{array}$ & SSRIs \\
\hline Taylor (2015) & 2005 & 7.7 & 2013 & 6.3 & $\nabla$ & USA & Overall \\
\hline Hurault-Delarue (2018) & 2005 & 2.0 & 2014 & 1.7 & $\Rightarrow$ & France & Overall \\
\hline Hanley (2014) & 2010 & 6.7 & 2011 & 6.4 & $\Rightarrow$ & USA & Overall \\
\hline Andrade (2016) & 2010 & 14.9 & 2013 & 10.8 & 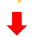 & USA & SSRIs \\
\hline
\end{tabular}

Narratively reported prevalence rates in the start year and end year of the cohort. Studies are sorted on start date of reported cohort. Arrows indicate an increase (green), stabilization (yellow) or decrease (red) of prevalence rates. A difference $<0.5 \%$ is regarded as stabilization.

2.32;2.34) using fixed-effects and 3.01\% (95\%CI 2.29;3.74) using random-effects calculations. For SNRIs, this was $0.35 \%$ (95\%CI $0.34 ; 0.36)$ and $0.73 \%(95 \% \mathrm{CI} 0.54 ; 0.92)$, and for TCAs $0.16 \%$ (95\%CI $0.16 ; 0.17)$ and $0.38 \%(95 \% \mathrm{CI} 0.29 ; 0.46)$ respectively.

The results of the sensitivity analysis for SSRI use during pregnancy are presented in Supplementary Figure 6 (Online Resource). Retrospective studies reported an almost four times higher prevalence (3.19\%) than prospective studies $(0.93 \%$; $p$-value $<0.01)$. Exposure defined by prescription/dispensing records showed an overall prevalence of $3.23 \%$, while exposure based on self-report had a prevalence rate of $1.53 \%$ ( $p$-value $=0.02$ ). No significant differences were seen in prevalence between studies including livebirths only, singletons only, or inclusion of consecutive pregnancies ( $p$-values between 0.21 and 0.48). Prevalence estimates stratified by the quality assessment of an appropriate sample frame indicated lower prevalence rates in appropriate sample frames $(2.20 \%)$ compared to non-appropriate sample frames $(3.85 \%$; $p$-value $<0.01)$. Studies with a detailed description of subjects and setting had a lower prevalence rate (3.02\%) compared to studies without $(4.20 \%$; $p$-value $<0.01$ ), although only two studies in this analysis lacked a detailed description (Taylor et al., 2015; Yamamoto-Sasaki et al., 2019).

Results of small-study assessment can be found in the Online Resource (Supplementary Fig. 7).

\section{Discussion}

Our findings demonstrate that the international use of antidepressants in the perinatal period depends on geographical region, type of antidepressant and certain methodological factors. SSRIs were the most commonly used antidepressant during pregnancy, with an international prevalence estimate of $3.0 \%$ (95\% CI 2.3;3.7) across a 26 year period (from 1989 to 2015). A qualitative increase in prevalence of antidepressants during pregnancy was noted. The most striking difference in prevalence estimates arose when stratifying by geographical region. While the countries in Europe and Australasia had pooled prevalence estimates of $1.6 \%$ and $1.3 \%$ respectively, Northern America had a prevalence estimate of $5.5 \%$. Unfortunately, no studies were available from Eastern European countries, or from developing geographical regions such as the Middle East, Central Asia and the African continent, perhaps as a result of the absence of central birth registers, linking pharmacy to birth records.

The observed differences in prevalence estimates for antidepressant use during pregnancy by geographical region may reflect differences in the prevalence and/or severity of underlying mental disorders leading to medication use. However, previous studies have demonstrated similar lifetime prevalence rates in English-speaking high-income countries and European high-income countries (Steel et al., 2014). It is more plausible that the geographical variations are due to local prescribing behavior of medication in general as well as prescribing behaviors specific to antidepressants. In addition, help-seeking behavior of the population and the organization of health care likely contribute to geographic variation in antidepressant use. For example, in the United States psychotherapy is often associated with out of pocket expenses. Moreover, people in the US use mental health services less than in other developed countries, while these services are consistently more expensive in the US than in comparably wealthy OECD countries (Sawyer and Sroczynski, 2016). The US has a lower number of psychologists (0.93) and psychiatrists (7.79) per 100,000 population than most comparable countries ( 31 psychologists and 18 psychiatrists per 100,000 on average) (Sawyer and Sroczynski, 2016). The bulk of mental health services for people with depression are therefore provided in primary care settings, who prescribe $79 \%$ of antidepressant medications (Barkil-Oteo, 2013). A survey amongst primary care physicians showed that two-thirds reported that they could not get outpatient mental health services for patients due to provider shortages, health plan barriers and lack of coverage, thereby affecting offered treatment methods (Cunningham, 2009).

Studies with detailed information on type of SSRI observed that sertraline was most frequently prescribed during pregnancy, followed by citalopram and fluoxetine. Sertraline is recommended for use during pregnancy by multiple guidelines due to its favorable profile during lactation (Pinheiro et al., 2015). Fluoxetine is not recommended as first choice due to its long half-life and presence in breastmilk. Use of paroxetine has been associated to an increased risk of congenital cardiovascular malformation, but this is not confirmed (Grigoriadis et al., 2013b). In general, guidelines discourage switching during pregnancy, even when using a non-preferred SSRI (Molenaar et al., 2018b).

When we stratified by definition of SSRI use, we found a higher prevalence estimate for studies using pharmacy records (prescription/ dispensing data) compared to studies relying on self-report. There is some evidence that self-reported psychiatric medication use is less accurate (Haapea et al., 2010; Van den Brandt et al., 1991), as a result of social desirability bias or self-stigmatization (Cotterchio et al., 1999; Nielsen et al., 2008; Rauma et al., 2013), but a recent large populationbased study showed the opposite: a very good agreement between antidepressant self-report and prescription data (Hafferty et al., 2018). The observed difference might therefore rather reflect a difference in included study population.

There was a trend for a decrease in prevalence for both SSRIs and TCAs from preconception to pregnancy, persisting into the second trimester. Many women are reluctant to continue antidepressants during pregnancy, because of potential negative consequences for the fetus, and express a preference for non-pharmacological treatment (Battle et al., 2013). Additionally, providers may counsel women to discontinue antidepressants in pregnancy due to fears of fetal exposure, sometimes unfortunately at the expense of maternal health and safety (Molenaar et al., 2018a). Approximately 50\% of women therefore decides to discontinue their medication, either shortly before pregnancy or during their first trimester (Molenaar et al., 2019). Since antidepressants are often not initiated during pregnancy, this results in lower prevalence rates in the second and third trimesters. But discontinuation patterns have changed over time, with fewer women discontinuing their antidepressants in the more recent calendar years (Molenaar et al., 2019). It is unclear whether this trend to continue more often is initiated by clinicians or pregnant women themselves. 
Current guidelines do not give clear recommendations regarding the continuation or discontinuation of antidepressant maintenance treatment throughout pregnancy (Molenaar et al., 2018a, 2018b), which is remarkable given the high prevalence of antidepressant use. Multiple recent studies in the general (non-pregnant) population showed equal efficacy of psychotherapy to antidepressant continuation in remitted patients (Bockting et al., 2018; Fava et al., 2004; Kuyken et al., 2015, 2008; Segal et al., 2010).

Lastly, we looked at prevalence rates over time. We used qualitative trend analysis from twelve cohorts since the included studies had limited quantitative information on prevalence rates per subsequent calendar year. While substantial increases in prevalence rates were observed in cohorts with a start date between 1992 and 2001, cohorts with a start date from 2004 onwards showed a stabilization or even small decrease in prevalence rates. This may indicate saturation of the market or reflect public opinion on the safety and efficacy of antidepressants during pregnancy. In contrast, prevalence rates in the general population were still rising in these later time periods (Hafferty et al., 2019; Pratt et al., 2017). The latter may, however, result both from an increased longer-term use by regular antidepressant users driving much of the increased reported prevalence, and from an increase in the aging population, who in general have a higher prevalence of antidepressant use (Pratt et al., 2017). Future studies are encouraged to quantitatively assess prevalence rates of antidepressants during pregnancy over time to adequately map longitudinal evolution of prescribing behavior in an international setting.

Our study has several limitations. We restricted our inclusion to articles written in English, and did not search grey literature, which may have contributed to the absence of data from low- and middleincome countries. We did not contact authors of excluded articles. In the estimation of prevalence rates per trimester, some women might have contributed information to multiple subgroups (when they continued medication throughout several trimesters), which underestimates the variation between groups. Furthermore, we found that substantial heterogeneity remained unaccounted for throughout the analyses, even after accounting for hypothetical contributors. Prevalence intervals were wide, predicting high variability in future studies.

The results of this meta-analysis indicate that antidepressant use during pregnancy is prevalent, with substantial variability based on geographical region and study population. Driving factors for geographical differences, such as health care service barriers and prescribing behavior, have to be identified in order to improve treatment management. Special emphasis should be placed on research examining the effectiveness of antidepressant maintenance treatment during the perinatal period to determine the justifiable prevalence rate of antidepressants. Furthermore, risks of discontinuation and use of other treatment and preventive options such as psychological interventions should be examined in rigorous trials. Only after we have an accurate estimate of the risks and benefits to both the fetus and the mother with continuation and discontinuation of antidepressants, as well as alternative therapies when discontinuing antidepressants, can we begin to develop evidence-based clinical guidelines for women with mental health illnesses and their providers.

\section{CRediT authorship contribution statement}

Nina M. Molenaar: Conceptualization, Data curation, Formal analysis, Writing - review \& editing. Babette Bais: Conceptualization, Data curation, Formal analysis, Writing - review \& editing. Mijke P. Lambregtse-van den Berg: Writing - review \& editing. Cornelis L. Mulder: Writing - review \& editing. Elizabeth A. Howell: Writing review \& editing. Nathan S. Fox: Writing - review \& editing. AnnaSophie Rommel: Writing - review \& editing. Veerle Bergink: Writing review \& editing. Astrid M. Kamperman: Conceptualization, Data curation, Formal analysis, Writing - review \& editing.

\section{Declaration of Competing Interest}

The authors declare no conflict of interests.

\section{Acknowledgment}

The authors thank Wichor Bramer, MSc, from Erasmus MC Medical Library for developing the search strategies.

\section{Funding}

This research did not receive any specific grant from funding agencies in the public, commercial, or not-for-profit sectors.

\section{Supplementary materials}

Supplementary material associated with this article can be found, in the online version, at doi:10.1016/j.jad.2019.12.014.

\section{References}

Andrade, S.E., Reichman, M.E., Mott, K., Pitts, M., Kieswetter, C., Dinatale, M., Stone, M.B., Popovic, J., Haffenreffer, K., Toh, S., 2016. Use of selective serotonin reuptake inhibitors (SSRIs) in women delivering liveborn infants and other women of childbearing age within the U.S. Food and Drug Administration's Mini-Sentinel program. Arch. Womens. Ment. Health 19, 969-977. https://doi.org/10.1007/s00737-0160637-1.

Barkil-Oteo, A., 2013. Collaborative care for depression in primary care: How psychiatry could "Troubleshoot" current treatments and practices. Yale J. Biol. Med. 86, $139-146$.

Battle, C.L., Salisbury, A.L., Schofield, C.A., Ortiz-Hernandez, S., 2013. Perinatal antidepressant use: understanding women's preferences and concerns. J. Psychiatr. Pract. 19, 443-453. https://doi.org/10.1097/01.pra.0000438183.74359.46.

Bockting, C.L.H., Klein, N.S., Elgersma, H.J., van Rijsbergen, G.D., Slofstra, C., Ormel, J., Buskens, E., Dekker, J., de Jong, P.J., Nolen, W.A., Schene, A.H., Hollon, S.D., Burger, H., 2018. Effectiveness of preventive cognitive therapy while tapering antidepressants versus maintenance antidepressant treatment versus their combination in prevention of depressive relapse or recurrence (DRD study): a three-group, multicentre, randomised controlled trial. Lancet Psychiatry 5, 401-410. https://doi.org/ 10.1016/S2215-0366(18)30100-7.

Boukhris, T., Sheehy, O., Mottron, L., Berard, A., 2016. Antidepressant use during pregnancy and the risk of autism spectrum disorder in children. JAMA Pediatr. 170 117-124. https://doi.org/10.1001/jamapediatrics.2015.3356.

Brown, H.K., Ray, J.G., Wilton, A.S., Lunsky, Y., Gomes, T., Vigod, S.N., 2017. Association between serotonergic antidepressant use during pregnancy and autism spectrum disorder in children. JAMA - J. Am. Med. Assoc. 317, 1544-1552. https://doi.org/ 10.1001/jama.2017.3415.

Charlton, R.A., Jordan, S., Pierini, A., Garne, E., Neville, A.J., Hansen, A.V., Gini, R., Thayer, D., Tingay, K., Puccini, A., Bos, H.J., Nybo Andersen, A.M., Sinclair, M., Dolk, H., De Jong-Van Den Berg, L.T.W., 2015. Selective serotonin reuptake inhibitor prescribing before, during and after pregnancy: A population-based study in six European regions. BJOG Int. J. Obstet. Gynaecol. 122, 1010-1020. https://doi.org/ 10.1111/1471-0528.13143.

Cooper, W.O., Willy, M.E., Pont, S.J., Ray, W.A., 2007. Increasing use of antidepressants in pregnancy. Am. J. Obstet. Gynecol. 196https://doi.org/10.1016/j.ajog.2007.01. 033. 544.e1-5.

Cotterchio, M., Kreiger, N., Darlington, G., Steingart, A., 1999. Comparison of self-reported and physician-reported antidepressant medication use. Ann. Epidemiol. 9, 283-289. https://doi.org/10.1016/S1047-2797(98)00072-6.

Cunningham, P.J., 2009. Beyond parity: primary care physicians' perspectives on access to mental health care. Health Aff. 28, w490-w501. https://doi.org/10.1377/hlthaff. 28.3.w 490 .

Daw, J.R., Hanley, G.E., Greyson, D.L., Morgan, S.G., 2011. Prescription drug use during pregnancy in developed countries: a systematic review. Pharmacoepidemiol. Drug Saf. 20, 895-902. https://doi.org/10.1002/pds.2184.

Fava, G.A., Ruini, C., Rafanelli, C., Finos, L., Conti, S., Grandi, S., 2004. Six-year outcome of cognitive behavior therapy for prevention of recurrent depression. Am. J. Psychiatry 161, 1872-1876. https://doi.org/10.1176/ajp.161.10.1872.

Figueroa, R., 2010. Use of antidepressants during pregnancy and risk of attention-deficit/ hyperactivity disorder in the offspring. J. Dev. Behav. Pediatr. 31, 641-648. https:// doi.org/10.1097/DBP.0b013e3181e5ac93.

Furu, K., Kieler, H., Haglund, B., Engeland, A., Selmer, R., Stephansson, O., Valdimarsdottir, U.A., Zoega, H., Artama, M., Gissler, M., Malm, H., Nørgaard, M., 2015. Selective serotonin reuptake inhibitors and venlafaxine in early pregnancy and risk of birth defects: population based cohort study and sibling design. Obstet. Gynecol. Surv. https://doi.org/10.1097/01.ogx.0000471597.68671.1e.

Grigoriadis, S., VonderPorten, E.H., Mamisashvili, L., Eady, A., Tomlinson, G., Dennis, C.L., Koren, G., Steiner, M., Mousmanis, P., Cheung, A., Ross, L.E., 2013a. The effect of prenatal antidepressant exposure on neonatal adaptation: a systematic review and 
meta-analysis. J. Clin. Psychiatry 74, e309-e320. https://doi.org/10.4088/JCP. 12 r07967.

Grigoriadis, S., VonderPorten, E.H., Mamisashvili, L., Roerecke, M., Rehm, J., Dennis, C.L., Koren, G., Steiner, M., Mousmanis, P., Cheung, A., Ross, L.E., 2013b. Antidepressant exposure during pregnancy and congenital malformations: is there an association? A systematic review and meta-analysis of the best evidence. J. Clin. Psychiatry 74, e293-e308. https://doi.org/10.4088/JCP.12r07966.

Haapea, M., Miettunen, J., Lindeman, S., Joukamaa, M., Koponen, H., 2010. Agreement between self-reported and pharmacy data on medication use in the Northern Finland 1966 Birth Cohort. Int. J. Methods Psychiatr. Res. 19, 88-96. https://doi.org/10. 1002/mpr.304.

Hafferty, J.D., Campbell, A.I., Navrady, L.B., Adams, M.J., MacIntyre, D., Lawrie, S.M., Nicodemus, K., Porteous, D.J., McIntosh, A.M., 2018. Self-reported medication use validated through record linkage to national prescribing data. J. Clin. Epidemiol. 94, 132-142. https://doi.org/10.1016/j.jclinepi.2017.10.013.

Hafferty, J.D., Wigmore, E.M., Howard, D.M., Adams, M.J., Clarke, T.-K., Campbell, A.I., MacIntyre, D.J., Nicodemus, K.K., Lawrie, S.M., Porteous, D.J., McIntosh, A.M., 2019. Pharmaco-epidemiology of antidepressant exposure in a UK cohort record-linkage study. J. Psychopharmacol. 33, 482-493. https://doi.org/10.1177/ 0269881119827888.

Hanley, G.E., Mintzes, B., 2014. Patterns of psychotropic medicine use in pregnancy in the United States from 2006 to 2011 among women with private insurance. BMC Pregnancy Childbirth 14, 242. https://doi.org/10.1186/1471-2393-14-242.

Higgins, J.P.T., Thompson, S.G., Spiegelhalter, D.J., 2009. A re-evaluation of randomeffects meta-analysis. J. R. Stat. Soc. Ser. A Stat. Soc. 172, 137-159. https://doi.org/ 10.1111/j.1467-985X.2008.00552.x.

Huybrechts, K.F., Bateman, B.T., Palmsten, K., Desai, R.J., Patorno, E., Gopalakrishnan, C., Levin, R., Mogun, H., Hernandez-Diaz, S., 2015. Antidepressant use late in pregnancy and risk of persistent pulmonary hypertension of the newborn. JAMA 313, 2142-2151. https://doi.org/10.1001/jama.2015.5605.

Hviid, A., Melbye, M., Pasternak, B., 2013. Use of selective serotonin reuptake inhibitors during pregnancy and risk of autism. N. Engl. J. Med. 369, 2406-2415. https://doi. org/10.1056/NEJMoa1301449.

Kieler, H., Artama, M., Engeland, A., Ericsson, O., Furu, K., Gissler, M., Nielsen, R.B., Nrøgaard, M., Stephansson, O., Valdimarsdottir, U., Zoega, H., Haglund, B., 2012. Selective serotonin reuptake inhibitors during pregnancy and risk of persistent pulmonary hypertension in the newborn: population based cohort study from the five Nordic countries. BMJ 344. https://doi.org/10.1136/bmj.d8012.

Kuyken, W., Byford, S., Taylor, R.S., Watkins, E., Holden, E., White, K., Barrett, B., Byng, R., Evans, A., Mullan, E., Teasdale, J.D., 2008. Mindfulness-based cognitive therapy to prevent relapse in recurrent depression. J. Consult. Clin. Psychol. 76, 966-978. https://doi.org/10.1037/a0013786.

Kuyken, W., Hayes, R., Barrett, B., Byng, R., Dalgleish, T., Kessler, D., Lewis, G., Watkins, E., Brejcha, C., Cardy, J., Causley, A., Cowderoy, S., Evans, A., Gradinger, F., Kaur, S., Lanham, P., Morant, N., Richards, J., Shah, P., Sutton, H., Vicary, R., Weaver, A., Wilks, J., Williams, M., Taylor, R.S., Byford, S., 2015. The effectiveness and costeffectiveness of mindfulness-based cognitive therapy compared with maintenance antidepressant treatment in the prevention of depressive relapse/recurrence: a randomised controlled trial (The PREVENT study). Lancet 386, 63-73. https://doi.org/ 10.1016/S0140-6736(14)62222-4.

Liberati, A., Altman, D.G., Tetzlaff, J., Mulrow, C., Gøtzsche, P.C., John, P.A., 2009. The PRISMA statement for reporting systematic reviews and meta-analyses of studies that evaluate healthcare interventions: explanation and elaboration. BMJ. https://doi. org $/ 10.1136 /$ bmj.b2700.

Liu, X., Agerbo, E., Ingstrup, K.G., Musliner, K., Meltzer-Brody, S., Bergink, V., MunkOlsen, T., 2017. Antidepressant use during pregnancy and psychiatric disorders in offspring: Danish nationwide register based cohort study. BMJ 358, j3668. https:// doi.org/10.1136/bmj.j3668.

Lugo-Candelas, C., Cha, J., Hong, S., Bastidas, V., Weissman, M., Fifer, W.P., Myers, M., Talati, A., Bansal, R., Peterson, B.S., Monk, C., Gingrich, J.A., Posner, J., 2018. Associations between brain structure and connectivity in infants and exposure to selective serotonin reuptake inhibitors during pregnancy. JAMA Pediatr. 172, 525-533. https://doi.org/10.1001/jamapediatrics.2017.5227.

Mitchell, A.A., Gilboa, S.M., Werler, M.M., Kelley, K.E., Louik, C., Hernández-Díaz, S., National Birth Defects Prevention Study, 2011. Medication use during pregnancy, with particular focus on prescription drugs: 1976-2008. Am. J. Obstet. Gynecol. 205https://doi.org/10.1016/j.ajog.2011.02.029. 51.e1-8.

Molenaar, N.M., Brouwer, M.E., Duvekot, J.J., Burger, H., Knijff, E.M., Hoogendijk, W.J., Bockting, C.L.H., de Wolf, G.S., Lambregtse-van den Berg, M.P., 2018a. Antidepressants during pregnancy: Guideline adherence and current practice amongst Dutch gynaecologists and midwives. Midwifery 61. https://doi.org/10. 1016/j.midw.2018.02.018.

Molenaar, N.M., Kamperman, A.M., Boyce, P., Bergink, V., 2018b. Guidelines on treatment of perinatal depression with antidepressants: an international review. Aust. N. Z. J. Psychiatry 52. https://doi.org/10.1177/0004867418762057.

Molenaar, N.M., Lambregtse-van den Berg, M.P., Bonsel, G.J., 2019. Dispensing patterns of selective serotonin reuptake inhibitors before, during and after pregnancy: a 16year population-based cohort study from the Netherlands. Arch. Womens Ment. Health. https://doi.org/10.1007/s00737-019-0951-5.

Munn, Z., Moola, S., Lisy, K., Riitano, D., Tufanaru, C., 2015. Methodological guidance for systematic reviews of observational epidemiological studies reporting prevalence and cumulative incidence data. Int. J. Evid. Based Healthc. 13, 147-153. https://doi.org/ 10.1097/XEB.0000000000000054

Munn, Z., Moola, S., Riitano, D., Lisy, K., 2014. The development of a critical appraisal tool for use in systematic reviews addressing questions of prevalence. Int. J. Heal. Policy Manag. 3, 123-128.

Naing, L., Winn, T., Rusli, B., 2006. Practical issues in calculating the sample size for prevalence studies. Arch. Orofac. Sci. 2006, 9-14.

Nielsen, M.W., Søndergaard, B., Kjøller, M., Hansen, E.H., 2008. Agreement between selfreported data on medicine use and prescription records vary according to method of analysis and therapeutic group. J. Clin. Epidemiol. 61, 919-924. https://doi.org/10. 1016/j.jclinepi.2007.10.021.

Nyaga, V.N., Arbyn, M., Aerts, M., 2014. Metaprop: a Stata command to perform metaanalysis of binomial data. Arch. Public Heal. 72, 1-10. https://doi.org/10.1186/ 2049-3258-72-39.

Pinheiro, E., Bogen, D.L., Hoxha, D., Ciolino, J.D., Wisner, K.L., 2015. Sertraline and breastfeeding: review and meta-analysis. Arch. Womens Ment. Health 18, 139-146. https://doi.org/10.1007/s00737-015-0499-y.

Pratt, L.A., Brody, D.J., Gu, Q., 2017. Antidepressant Use Among Persons Aged 12 and Over: United States,2011-2014. NCHS Data Brief 1-8.

Rauma, P.H., Koivumaa-Honkanen, H., Kröger, H., Tuppurainen, M.T., Kauhanen, J., Honkanen, R.J., 2013. The relationship between self-reported and registry-based data on use of psychoactive medications in postmenopausal women. BMC Psychiatry 13, 180. https://doi.org/10.1186/1471-244X-13-180.

Ross, L.E., Grigoriadis, S., Mamisashvili, L., Vonderporten, E.H., Roerecke, M., Rehm, J., Dennis, C.-L., Koren, G., Steiner, M., Mousmanis, P., Cheung, A., 2013. Selected pregnancy and delivery outcomes after exposure to antidepressant medication: a systematic review and meta-analysis. JAMA Psychiatry 70, 436-443. https://doi.org/ 10.1001/jamapsychiatry.2013.684.

Sawyer, B., Sroczynski, N., 2016. How do U.S. health care resources compare to other countries?

Segal, Z.V., Bieling, P., Young, T., MacQueen, G., Cooke, R., Martin, L., Bloch, R., Levitan, R.D., 2010. Antidepressant monotherapy vs sequential pharmacotherapy and mindfulness-based cognitive therapy, or placebo, for relapse prophylaxis in recurrent depression. Arch. Gen. Psychiatry 67, 1256-1264. https://doi.org/10.1001/ archgenpsychiatry.2010.168.

Simoncelli, M., Martin, B.-Z., Berard, A., 2010. Antidepressant use during pregnancy: a critical systematic review of the literature. Curr. Drug Saf. 5, 153-170. https://doi. org $/ 10.2174 / 157488610790936114$.

Steel, Z., Marnane, C., Iranpour, C., Chey, T., Jackson, J.W., Patel, V., Silove, D., 2014. The global prevalence of common mental disorders: a systematic review and metaanalysis 1980-2013. Int. J. Epidemiol. 43, 476-493. https://doi.org/10.1093/ije/ dyu038.

Taylor, L.G., Thelus Jean, R., Gordon, G., Fram, D., Coster, T., 2015. Development of a mother-child database for drug exposure and adverse event detection in the Military Health System. Pharmacoepidemiol. Drug Saf. 24, 510-517. https://doi.org/10. 1002/pds.3759.

Van den Brandt, P.A., Petri, H., Dorant, E., Goldbohm, R.A., Van de Crommert, S., 1991. Comparison of questionnaire information and pharmacy data on drug use. Pharm. Weekbl. Sci. 13, 91-96. https://doi.org/10.1007/bf01974987.

van Gelder, M.M.H.J., Bos, J.H.J., Roeleveld, N., de Jong-van den Berg, L.T.W., 2014. Drugs associated with teratogenic mechanisms. Part I: dispensing rates among pregnant women in the Netherlands, 1998-2009. Hum. Reprod. 29, 161-167. https://doi.org/10.1093/humrep/det369.

Wichman, C.L., Moore, K.M., Lang, T.R., St. Sauver, J.L., Heise, R.H., Watson, W.J., 2009. Congenital heart disease associated with selective serotonin reuptake inhibitor use during pregnancy. Mayo Clin. Proc. 84, 23-27. https://doi.org/10.4065/84.1.23.

Yamamoto-Sasaki, M., Yoshida, S., Takeuchi, M., Tanaka-Mizuno, S., Ogawa, Y., Furukawa, T.A., Kawakami, K., 2019. Association between antidepressant use during pregnancy and autism spectrum disorder in children: a retrospective cohort study based on Japanese claims data. Matern. Heal. Neonatol. Perinatol. 5, 1. https://doi. org/10.1186/s40748-018-0096-y. 